\title{
Drugs Regulation in Telangana State India: A Overview
}

\author{
Kempaiah Suresh ${ }^{1}$, Balamuralidhara V², T.M. Pramod Kumar ${ }^{3}$, \\ ${ }^{I}$ Research Scholar Regulatory Affairs Group, Department of Pharmaceutics, JSS College of Pharmacy, JSS \\ University, Sri Shivarathreeshwara Nagara, Mysore - 570 015, Karnataka, India \\ ${ }^{2}$ Assistant Professor Regulatory Affairs Group, Department of Pharmaceutics, JSS College of Pharmacy, JSS \\ University, Sri Shivarathreeshwara Nagara, Mysore - 570 015, Karnataka, India \\ ${ }^{3}$ Professor Regulatory Affairs Group, Department of Pharmaceutics, JSS College of Pharmacy, JSS University, \\ Sri Shivarathreeshwara Nagara, Mysore - 570 015, Karnataka, India
}

\begin{abstract}
Pharmacy is the health profession that links the health science with chemical science and it is charged with ensuring the safe and effective use of pharmaceutical drugs. Telangan has Drugs Control Department independent of the Health Department and the Heads of these Departments are reporting to the Government directly. The State of Telangana as some of the country's most dynamic entrepreneurs who are original and fast-paced in their thinking and focused in their drive for growth and profitability. Telangana is one of the most industrialised states in the country.. It has a strong base of educational institutions imparting courses in Pharmacy and some of the institutions have international repute to its credit. Telangana is one of the fastest growing states in the Country and nearly 400 pharma and biotech companies and 33000 Retail and Wholesale are housed in the State. Telangana is a vibrant pharmaceutical manufacturing hub for Bulk Drugs fortified with sound knowledge based institutions and skilled human resource available in the state, it provides innovative, quality and affordable health care solution to masses. In this short review author provides some of the glimpses of the pharmacy profession in Telangana.
\end{abstract}

Keywords: Pharmacy profession, Telangana, Education, Health, Drug.

\section{TELANGANA}

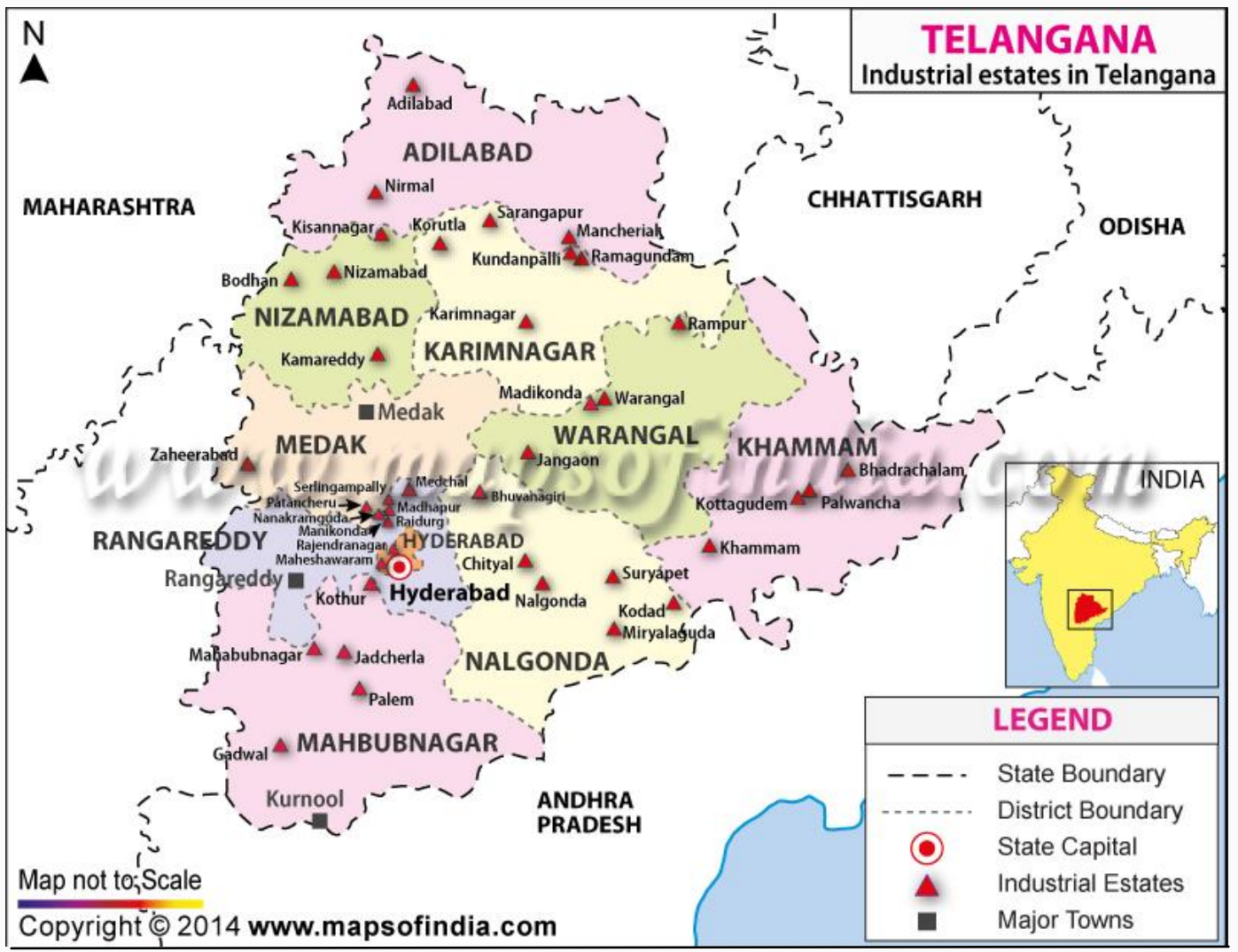




\section{Introduction}

Telangana is one of the 29 states in India, located in southern India. Telangana has an area of 112,077 square kilometres (43,273 sq mt) and a population of 35,193,978 (2011 census). Making it the twelfth largest state in India, and the twelfth most populated state in India. Telangana consists of following major cities which include Hyderabad, Warangal, Nizamabad, Khammam, Karimnagar and Ramagundam. Telangana is bordered by the states of Maharashtra to the north and North West, Chhattisgarh to the north, Karnataka to the west and Andhra Pradesh to the east and south. Telangana acquired its identity as the Telugu-speaking region of the princely state of Hyderabad, ruled by the Nizam of Hyderabad, joining the Union of India in 1948. In 1956, the Hyderabad state was dissolved as part of the linguistic reorganisation of states and Telangana was merged with former Andhra State to form Andhra Pradesh. Following a movement for separation, it was awarded separate statehood on 2 June 2014. Hyderabad will continue to serve as the joint capital city for Andhra Pradesh and Telangana for a period of not more than ten years. ${ }^{1}$

\section{- History}

\section{Drugs Control Administration Telangana}

The Drugs Control Administration was extended to Telangana region after the formation of Andhra Pradesh State in the year 1956 when four Drugs Inspectors were appointed and implementation of Drugs \& Cosmetics Act was extended to this area.

Subsequently, Drugs Control Administration was also entrusted with the enforcement of Prevention of Food Adulteration Act and the Head of the Department was designated as Drugs Controller and Food Health Authority. In the year 1981 the Department of Drugs Control Administration was accorded independent status with a separate Directorate headed by a Director functioning under the Ministry of Medical and Health.

\section{- Drugs Control Administration was extended to Telangana}

The organizational set up of various functionaries in Drugs and Control Administration are broadly classified into two wings.

1.EnforcementWing

2. Laboratory Wing.

Enforcement Wing performs the functions of enforcement of the above legislations in the State and Laboratory Wing performs the Test/Analysis of various Drugs/Cosmetics samples sent for analysis and issues the Certificate of Test/Analysis.

In 1976, FDA was carved out from the Directorate of Medical and Health, headed by an IPS Officer till 1981. Drugs Control Administration, A.P was separated from the office of the Drugs Controller \& State Food Health Authority in the year 1981 and was made an independent Department headed by Director, DCA till 1996.

In Aug 1996, Govt. had posted an IPS officer of the rank of Inspector General of Police, Drugs and Copyright to head the DCA. Subsequently this post was upgraded to ADGP/DGP level as the HOD.

After the bifurcation of erstwhile Andhra Pradesh state, the Drugs Control Administration department of Telangana State was setup on 02.06.2014.

- Organisation chart

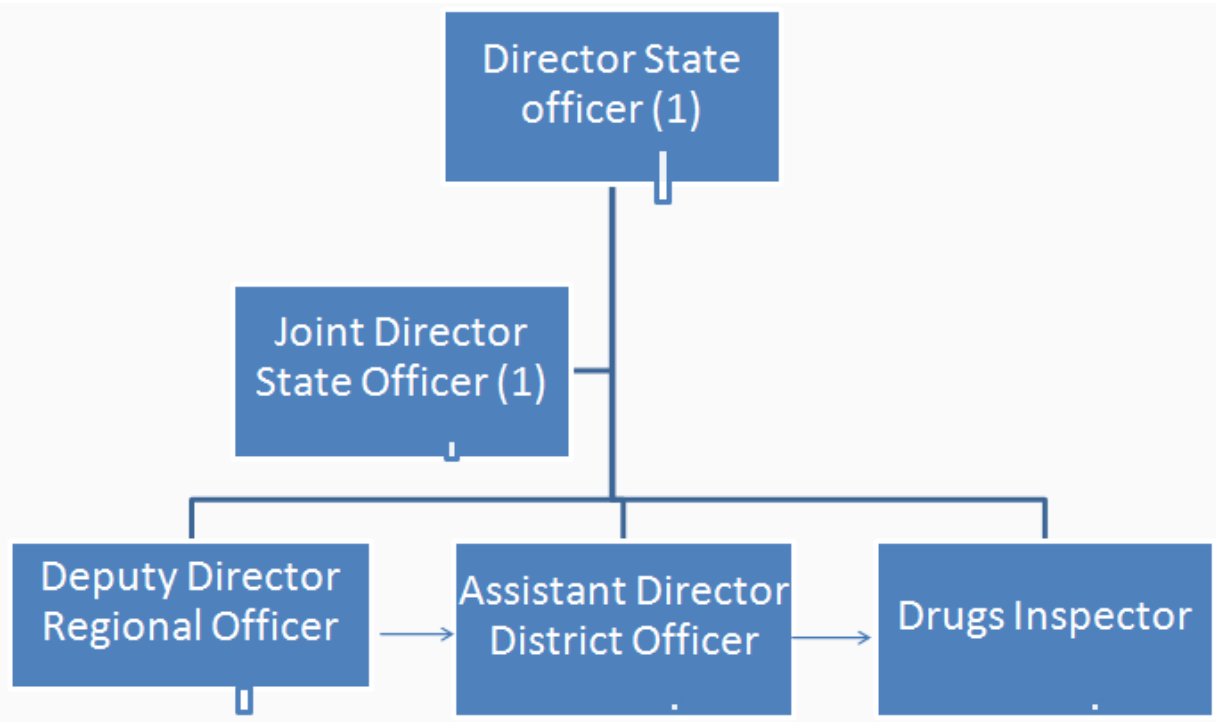


Drugs Control Administration - Head Quarters Assitant Director -I, II, III

Two Assistant Director (TC) at Head Office

Sales establishment - All the district are headed by Assistant Director and under them Drugs Inspector and supporting staff are working

Drugs Control Administration - Medak District

Drugs Control Administration - Mahabubnagar District

Drugs Control Administration - Nalgonda District

Drugs Control Administration - Nizamabad District

Drugs Control Administration - Khammam District

Drugs Control Administration - Warangal Distric

Drugs Control Administration - Karimnagar District

Drugs Control Administration - Adilabad District

- $\quad$ The main objective of Drugs Control Administration is to ensure that the drugs that are made available to the public, who use them for prevention, mitigation or treatment of diseases are of the required standards of quality, purity and strength and are packed in containers giving all necessary information about the drug and its manufacturer. Drugs control Administration regulates the manufacture, sale and distribution of drugs in the state of Telangana by implementing the following central legislations throughout the state.
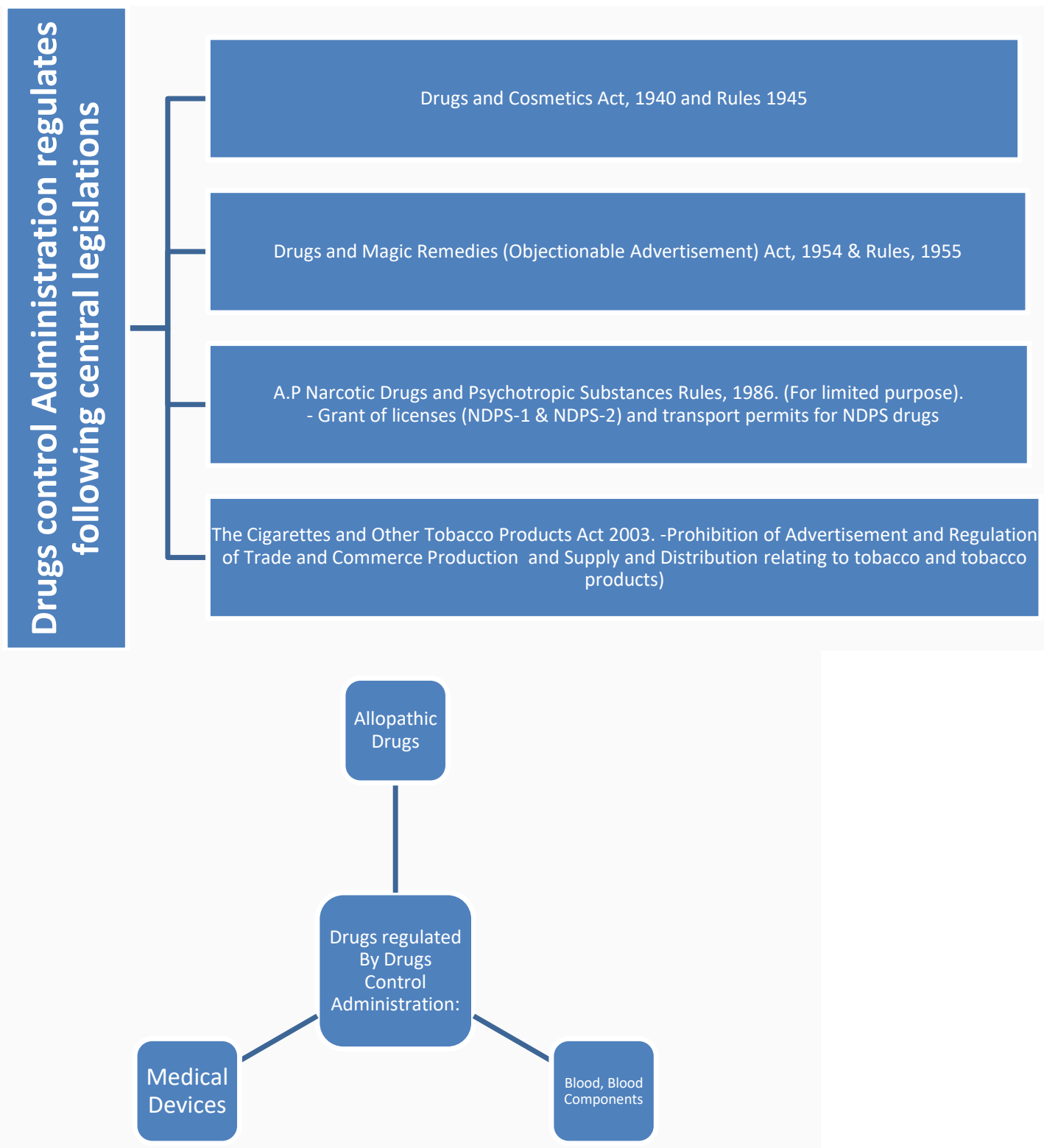
- Objective of the Drugs Control Administration:

- To ensure safety, efficacy, purity and quality of Drugs.

- To prevent consumers from self-medication.

- To ensure availability of drugs at authorized prices.

- To create an awareness about the importance of proper storage of drugs.

- To eliminate irrational combinations /banned drugs.

- To study the problems and suggestions made by the stakeholder.

- To collect the information in general about the drug trade and take necessary steps.

- To prepare policy regarding drug matter.

- To prevent misuse of Narcotics drugs

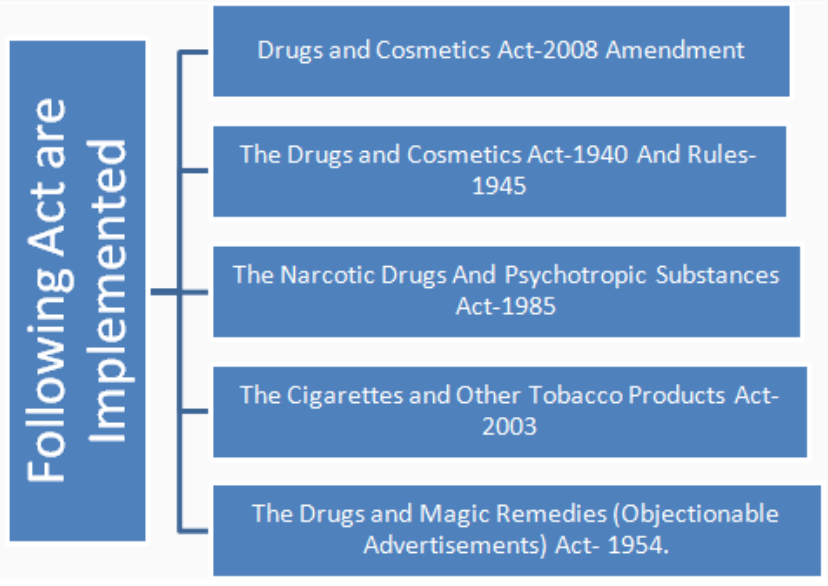

There are about Sales Firms $=\mathbf{2 8 0 0 0}$ Retailers 5000 Wholesalers, in Telangana

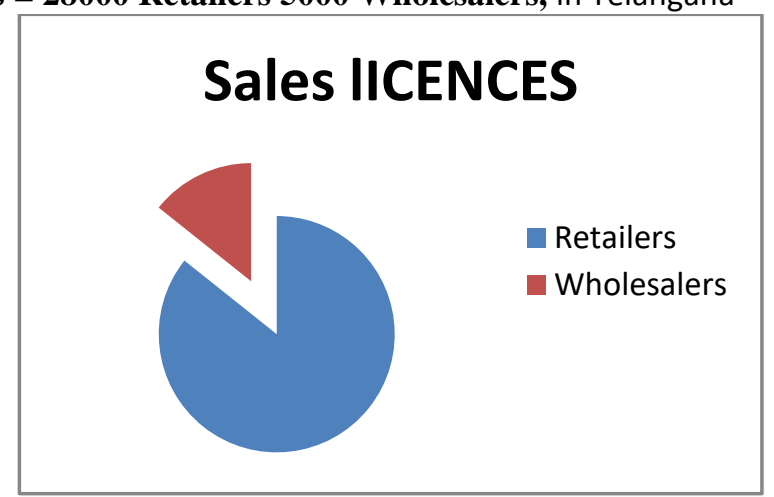

Services offered by Department:

\begin{tabular}{|l|l|l|}
\hline S.No & Item of work targeted & $\begin{array}{l}\text { Maximum } \\
\text { (In no. of working days) }\end{array}$ \\
\hline 1 & Grant of manufacturing licenses & 30 \\
\hline 2 & Renewal of Manufacturing licenses & 30 \\
\hline 3 & Grant/Renewal of approval for Approved Laboratories & 30 \\
\hline 4 & Approval of Additional products & 10 \\
\hline 5 & Approval of Technical Staff & 10 \\
\hline & $\begin{array}{l}\text { Recommending for Grant/Renewal of Licenses to Central Licensing } \\
\text { Authority, Delhi with respect to Vaccines and serarge Volume }\end{array}$ & \\
\hline 6 & parenterals:Blood & 30 \\
\hline 7 & Effecting changes in existing licenses & 10 \\
\hline 8 & Issue of free sale Certificate & 5 \\
\hline 9 & Issue of Market Standing Certificate & 5 \\
\hline 10 & Issue of GMP Certificate & 10 \\
\hline 11 & Issue of Non-Conviction Certificate & 5 \\
\hline 12 & Issue of Production capacity Certificate & 5 \\
\hline 13 & Issue of WHO GMP Certificate & 20 \\
\hline 14 & Issue of test licenses & 15 \\
\hline
\end{tabular}


There are about 468 Manufacturing Licences

Ther are about 132 Blood Banks and 35 Blood Storage Units in Telangana $(2,3)$

\section{Manufacturing and Blood Banks and Storage Centres}

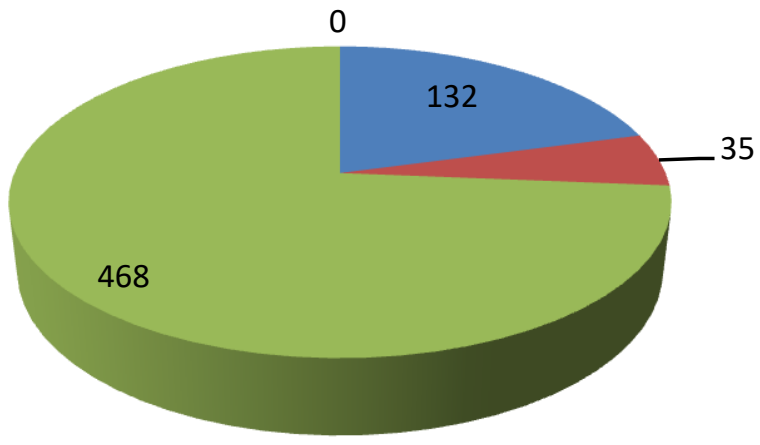

Blood Banks

Blood Storage Centres

Manufacturing Units

\section{Pharmaceutical Industry}

- HYDERABAD - Vibrant and Progressive Hyderabad, joint capital of Telangana \& Andhra Pradesh, is the sixth largest urban agglomeration of India. Hyderabad has a dominant position in Pharma Sector, it ranks first in manufacturing of bulk drugs and third in formulations in the country. It accounts for 40 per cent of the total Indian bulk drug production and 50 per cent of the bulk drug exports and is considered as the 'Bulk Drug Capital of India'. In value terms, the industry is worth US\$ 1.6 billion and exports accounting to over US\$ 500 million. The Pharma industry and exports from here are expected to grow at 20 per cent annually. Telangana is a home to few of the top pharma companies Viz. Dr. Reddy's Laboratories, Aurobindo pharmaceuticals, Mylan, Novartis, Nicholas Piramal, Divi Labs, NATCO Pharma, Gland Pharmaceuticals, etc. There are more than 200 'Active Pharmaceutical Ingredients (API)' units in the state, which are poised to grow at a rate of 10 to 15 per cent annually in the coming days. Hyderabad is also referred to as the 'Vaccine Hub of India'. The city is home to leading vaccine producers such as Bharat Biotech, Biological E, Shantha Biotech, Indian Immunologicals, Globion Bio among others. The Clinical Trial sector in Hyderabad has also witnessed a steep rise, with leading clinical trial companies such as GVK Biosciences, Sipra, Vimta Labs and Quintiles among others.

- $\quad$ Evolution \& Growth of Pharma Industry in Hyderabad

Hyderabad has grown into a pharma hub for bulk drugs basically for two reasons, firstly due to establishment of Indian Drugs and Pharmaceuticals Ltd. (IDPL) and secondly due to the enterprising nature of its people and availability of adequate talent pool in the state. Indian Drugs and Pharmaceuticals Ltd. (IDPL) was set up in the year 1961 at the behest of India's first Prime Minister, Pandit Jawaharlal Nehru as India's largest public sector drug maker in the early days, to enable the country attain self-sufficiency in life-saving drugs. In 1977 the government has established an industrial estate at Jeedimetla in Hyderabad, to develop ancillary units for IDPL. This started off a growth phase of the pharma cluster here. The proactive steps and availability of infrastructure has attracted lot of Technical talent into the industry. Large number of current MSME entrepreneurs here are technocrats who have working experience with large or medium pharma firms and Organizations. The units started in small way and rapidly graduated to the next level Dr. Reddy's Lab, Aurobindo Pharma, Natco, Divi's Lab, Matrix, SuvenPharma, Vimta Lab, Neuland Laboratories, etc. are now internationally recognized names.

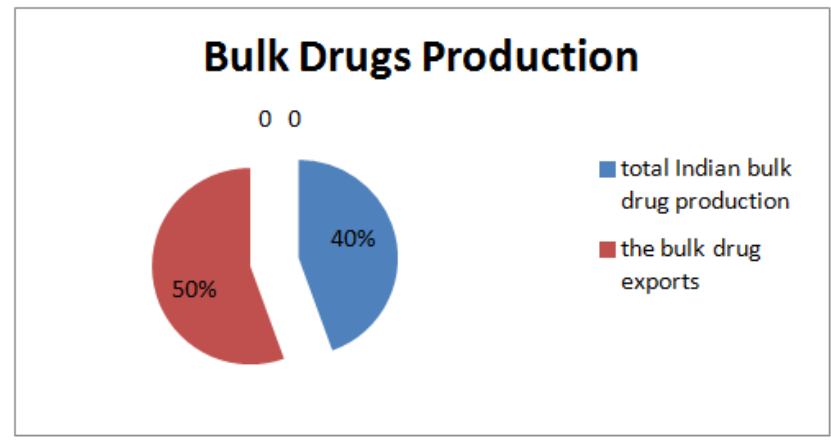


Dr Reddy's Laboratories Established in the year 1984, Aurobindo Pharma is a manufacturer of generic pharmaceuticals and APIs. Matrix Laboratories Matrix Laboratories is a public limited company manufacturing APIs and solid oral dosage forms based in Secunderabad. Divis Laboratories established in the year 1990, is a Hyderabad-based pharma company, known for making APIs and intermediates, apart from contract manufacturing. Suven Life Sciences is based in Hyderabad. Bharat Biotech International Bharat Biotech International (BBI), Hyderabad, is a multidimensional biotechnology company specialising in product-oriented research, development and manufacturing of vaccines and biotherapeutics. Shantha Biotechnic Ocimum Biosolutions is an integrated global genomic services company with operations in Hyderabad and Gaithersburg, Maryland, US. Transgene Biotek Transgene Biotek was probably the first true biotech company in India. It is listed on the Indian Stock Exchanges and is involved in the development of several cutting edge technologies.

\section{Telangana Pharmacy Council}

The Government of Andhra made 'Andhra State Pharmacy Council Rules, 1955'by G.O.Ms.1021, Director of Medical health Services, Sultanbazar, Hyderabad, Dated $9^{\text {th }}$ July 1955 in accordance with powers u/s 46 of The Pharmacy Act, 1948. Subsequently I came into existence by .O.Ms. 2073. Health, dated $15^{\text {th }}$ July 1963 as Andhra Pradesh Pharmacy Council Rules, 1955.

The Government of Andhra vide G.O. Ms. No.891, Health dated $8^{\text {th }}$ December 1955 vide powers u/s 33A (4) of The Pharmacy Act, 1948 directed the Registrar Madras Pharmacy Council to prepare First register. It was published in the year 1956 with a list of 236 Pharmacists who were practicing pharmacy in the erstwhile state of Andhra. Presently the registration of pharmacists is around 70000. Now that the Council is functioning under In-charge, Director, Drugs Control Administration, Government of Telangana. After the formation of the Telangana State, the Andhra Pradesh state pharmacy council has shifted its office to Guntur. However they are now registering the pharmacist 3 days at Hyderabad and 3 days at Guntur. The State government has formed the Telangana State Pharmacy Registration Tribunal, Nampally, Hyderabad, Telangana for the registration of pharmacist. There are about more than 60 colleges in Telangana State. $(5,6)$

\section{Conclusion}

The pharmacy education in Telangana has witnessed tremendous expansion in last one decade. We have Seventy thousands of pharmacists in the state. The entire spectrum of the pharmacy related activities in Telangana are brought under one roof, i.e., drugs control administration, pharmacy education, pharmaceutical Industry and trade business establishment for all around the development of pharmacy from the inception of it.

\section{Acknowledgement}

I would like to thank Sri Rajbhanu Assiatnat Director Drugs Control Adminsitration Telangana for providing the learning's that made this manuscript in the best mode form.

\section{Conflicts Of Interest}

- The Author declares that there are no conflicts of interest.

\section{References}

[1]. Profile of Telanaga [Internet], Telangana [cited 2017 Jan 5] - Available from:Wikipedia https://en.wikipedia.org/wiki/Telangana

[2]. Drugs Control Administration, Telangana [Internet] [cited 2017 Jan 8] Available from: PDF]GOVERNMENT OF ANDHRA PRADESH DRUGS CONTROL ... - inogent inogent.com/images/GMP-Certificate-2011.pd

[3]. Drugs Control Administration, Government of Telangana [Internet] [cited 2017 Jan 8] Available from:www.dca.telangana.gov.in/

[4]. Telangana Pharameuctical Industry [Internet] [cited 2017 Jan 8] Available from:PHARMAHITEXwww.hitex.co.in/downloads/Industry\%20Reports\%20on\%20Pharmaceutical\%20Industry.pdf

[5]. Information on Telangana pharmacy council [Internet] [cited 2017 Jan 15] Available from:Official Website of Pharmacy Council appharmacycouncil.gov.in/site/bpharmreg

[6]. Central Council - Pharmacy Council of India [Internet] [cited 2017 Jan 8] Available from:http://pci.nic.in/CouncilMembers/CentralCouncil.aspx 